S. Barney, A. Aurum and C. Wohlin, "Quest for a Silver Bullet: Creating Software Product Value through Requirements Selection", Accepted for publication in Proceedings of Euromirco Conference on Software Engineering and Advanced Applications, track on Software Process and Product Improvement, Cavtat/ Dubrovnik, Croatia, 2006. Selected for special issue of J ournal of Systems Architecture. 


\title{
Quest for a Silver Bullet: Creating Software Product Value through Requirements Selection
}

\author{
Sebastian Barney ${ }^{1}$ Aybüke Aurum ${ }^{1}$, Claes Wohlin ${ }^{2}$ \\ ${ }^{1}$ School of Information System, Technology and Management \\ University of New South Wales, Sydney NSW 2052, Australia \\ sebastian.barney@student.unsw.edu.au,aybuke@unsw.edu.au \\ ${ }^{2}$ School of Engineering Blekinge Institute of Technology, \\ PO Box 520, SE372 25, Ronneby, Sweden \\ claes.wohlin@bth.se
}

\begin{abstract}
This paper provides results of an empirical study on how software product value is both understood and created through release planning for software products in Australia. We examine how IT professionals perceive value creation through requirements engineering and how the release planning process is conducted to create software product value. We then look at the degree to which the major stakeholders' perspectives are represented in the decision making process. Our findings show that the client and market base of the software product represents the most influential group in the decision to implement specific requirements. This is reflected both in terms of deciding the processes followed and the decisionmaking criteria applied when selecting requirements for the product. It is concluded that the creation of software product value is dependant on the context in which the software product exists, including issues such as the market or the age of the product.
\end{abstract}

\section{Introduction}

Market driven incremental software development is increasingly becoming commonplace $[6,13]$. Software in this category is developed and released to meet the requirements of a particular market, yet it continues to evolve with future releases. This may be to meet the needs of new markets or to meet the changed needs of the existing customers. Each iteration aims to deliver a new set of features or requirements.

The requirements for software are often so numerous that they cannot all be included in the next release. This makes it necessary to select a set of high priority requirements to implement for the next release, and to postpone the implementation of the remaining requirements. This process is called release planning.

Value-based requirements engineering (VBRE) aims to maximize the value of a release of software through the selection and prioritization of requirements
[17]. While most release planning literature covers prioritization and dependencies between requirements $[6,7,8,10,13]$, there has been little research into the criteria used in this decision-making process [17].

This article presents the results of an empirical study, based on data collected from two software projects from an Australian company. The main objective of this paper is to provide insight into the release planning processes used in industry to create software product value. The study addresses both the process followed and the criteria used in the decision making process. This research highlights different stakeholders' roles and their influences on this process. To the best of our knowledge, there are no other field studies that examine VBRE practices in Australian companies. The contribution of this paper is four fold; a) investigates how VBRE is perceived by practitioners, b) examines how industry conducts release planning, c) studies the values applied in prioritization of requirements, d) examines to what degree stakeholders' perspectives influence the prioritization of requirements.

The rest of this paper is organized as follows: Section 2 covers background knowledge on the valuebased approach in software development. Section 3 presents the methodology. Section 4 presents the results of data analysis. Section 5 provides a detailed discussion while Section 6 addresses validity treats. Finally, Section 7 concludes the paper.

\section{Literature Review}

\subsection{Defining Value}

According to Boehm [3] software engineering (SE) is largely practiced in a value neutral setting - every requirement is considered equally important, even though not all requirements are equal.

Projects are tracked using earned value systems, monitoring project cost and schedule. This approach does not consider stakeholder and business value. A 
project can be very successful in its cost oriented earned value, but fail to provide any business value.

Product value in economics is described as the worth in monetary terms of the technical, economic, service and social benefits a customer receives in exchange for the price it pays for goods and/or services [2]. In this definition benefits refer to net benefits, in which any costs (other than that paid for the product) are taken into account. This definition otherwise separates the price paid for a product from the value it provides. Thus changing the price of a product does not change its value, but alters the customers' incentive to purchase it.

Management literature considers customer value from two perspectives; absolute value (how well a product meets a customer's needs) and relative value (the value of a product relative to the alternative solutions available) [5]. Similarly marketing literature describes value as the relationship between the needs of a customer and the benefits a product offers that satisfy those needs. But they also recognize the need to consider all stakeholders when assessing value [1].

Nunamaker et al. [12] approach the issue from a SE perspective, describing something as having value if one considers it useful, convenient or essential. Thus, value can only be defined from a particular point of view. As each stakeholder has their own needs, wants and desires organizations create value along many dimensions, including economic, physical, emotional, social, cognitive and political dimensions.

Today software has a major effect on the cost, value and schedule of a project [3]. But an organization's success in terms of profitability or market capitalization does not correlate with their level of investment in IT [16]. That is just because spending occurs does not automatically mean benefits are realized. Most studies that look into the critical success factors in successful and failed projects have found that the primary critical success factors lie in the value domain. The majority of software development projects fail due to a lack of user input, incomplete requirements, lack of resources, unrealistic expectations, unclear objectives and/or unclear timeframes $[3,14,15]$.

\subsection{Aligning Release Planning and Value Perspectives}

Many stakeholders are involved in software product development, each with their own perspective on value in the software development process [4]. For example, a project sponsor defines value in terms of the cost of the software and the benefits it provides; a software company measures value in profit; while a user looks at how well the software meets their needs. These perspectives are often incompatible, and must be reconciled [4]. For example:

- Users of the software want many features, while the project sponsor wants to limit cost by minimizing the development effort;

- Developers want stable requirements, but users want to be able to change the requirements; and

- The system maintainers want their job to be made easier, but the developers and project sponsors want control over the solution provided.

Maurice et al. [11] recognized that while iterative development facilitates early customer feedback, allowing faster delivery and a more interactive process; it also creates difficulties with reconciling conflicting stakeholder perspectives. VBRE exploits the concept of economic value during the requirements engineering (RE) process [9]. Boehm [3, 4] states that in order to achieve this; VBRE must include practices and principles for: identifying stakeholders and eliciting their value propositions and reconciling these propositions into a set of mutually agreed objectives for the system.

It is also important to consider that the value market places on different requirements change over time [11]. The critical success factor for software vendors is their ability to respond quickly to changing requirements while maintaining a focus on their value proposition (e.g. a quicker return on investment).

One of the most important activities in incremental development is to decide upon the most appropriate release plan [13]. VBRE aims to maximize the value of a release of software to success-critical stakeholders through the selection of requirements [17]. There has been little research into the criteria used in the decision-making process used to achieve this goal [17] or how different stakeholders' value propositions are represented in the RE process.

\section{Methodology}

The main purpose of this study is to understand how software product value is created through the RE process. The following research questions are considered in this research.

RQ1: How is VBRE perceived by the software development industry?

RQ2: How does the software industry conduct release planning in order to create product value?

RQ3: What values are applied to the decision making process to select and prioritize requirements for a software project or release? How does this differ to industry perceptions of the optimal application of the criteria?

RQ4: To what degree do the perspectives of the major stakeholders influence the requirements 
selection and prioritization process? How does this differ to industry perceptions of the optimal application of the criteria?

This study employed a mixed research methodology to investigate two software products from an Australian company. Each product was investigated in three stages: semi-structured interviews, questionnaires followed by a confirmation and review of the results in unstructured interviews. The purpose of the interview was to understand how industry perceives and creates software product value through the RE process, while the purpose of the questionnaire was to understand what defines whether a requirement will be included in a specific release or project. The results from the interview and questionnaire were then presented to selected participants for their comment in an unstructured interview. The participants were asked to verify and explain the results. The interview questions were constructed based on the key activities in the RE and release planning processes and the interviewees' perceptions of how to create software product value through RE. We conducted 4 interviews for Product A1 and 2 interviews for Product A2.

Table 1 Criteria and Perspectives

\begin{tabular}{|c|c|}
\hline Perspectives & Criteria \\
\hline $\begin{array}{l}\text { Business } \\
\text { (external } \\
\text { customers \& } \\
\text { markets) }\end{array}$ & $\begin{array}{l}\text { 1. Competitors } \\
\text { 2. Requirement's issuer } \\
\text { 3. Stakeholder priority of requirement } \\
\text { 4. Function is promised/sold } \\
\text { Explanation: The expectation of } \\
\text { stakeholders to see the requirement met is } \\
\text { taken into account. } \\
\text { Motivation: We may want to include } \\
\text { requirements that were promised or sold } \\
\text { to meet stakeholder expectations. } \\
\text { 5. Volatility }\end{array}$ \\
\hline $\begin{array}{l}\text { Management } \\
\text { (internal, } \\
\text { related to } \\
\text { project issues), }\end{array}$ & $\begin{array}{l}\text { 6. Support/Education/Training } \\
\text { 7. Development cost-benefit } \\
\text { 8. Resources/competencies } \\
\text { 9. Delivery date/Calendar time }\end{array}$ \\
\hline $\begin{array}{l}\text { System } \\
\text { (internal related } \\
\text { to technical } \\
\text { solutions \& } \\
\text { development) }\end{array}$ & $\begin{array}{l}\text { 10. System impact } \\
\text { 11. Complexity } \\
\text { 12. Requirements dependencies } \\
\text { 13. Evolution } \\
\text { 14. Maintenance }\end{array}$ \\
\hline
\end{tabular}

The questionnaire was adopted from the Wohlin and Aurum study [17, 18] and focused on the criteria used for selecting software requirements to create value. The questionnaire included 14 criteria that covered 3 different perspectives, as shown in Table 1. The questionnaire asked the respondents to modify the list. First the respondents were asked to identify any additional criteria not listed. Then the respondents were asked to mark the criteria they felt were relevant in deciding whether to include a requirement in a release or project. Finally the respondents were asked to provide relative weights regarding the importance of the criteria in two sets, currently and if the criteria were applied optimally. The respondents had 1000 points to spend amongst the criteria. A high number of points meant a criterion was important.

The questionnaire was sent to 14 employees of the organization that were in a role that provided them with decision-making capacity with respect to the selection of requirements for Products A1 and A2. The return rate of questionnaire, for Product A1, was 100\%, while for Product A2 it was $72 \%$. The importance of each criterion, both at present (today) and in the future (optimal), were analyzed by summing all the points for each criterion and normalizing the result for each criterion to a percentage. To analyze the importance of different stakeholder perspectives each criterion was placed into one of three groups - external market/customer, company management, and development/maintenance - dependant on which perspective it represented.

\section{Results}

\subsection{Product Descriptions}

This research presents an in depth analysis of two software products from an outsourcing company (Company A) that operates primarily in Australia. The company's client base represents a diverse range of industry i.e. telecommunications, finance, government and retail. The company employs approximately 1000 permanent staff in seven offices nationwide, of which about 200 are in IT or IT related roles. The first author of this article has worked at Company A as an IT Consultant in client implementations. The researcher made direct contact with the participants (subjects) to organize interview times and distribute questionnaires.

Product A1 was a large-scale document and data repository developed and supported by Company A. The product has been undergoing iterative development for over ten years. It was in its third major release, with the fourth release due in late 2005 .

Product A2 provided a solution for managing the collection, analysis and processing of paper requests and responses such as election polls, surveys, exams, insurance claims, remittances and general inbound mail. It was developed, hosted and supported by Company A. The product has been undergoing iterative development over two years. At the time of the study the company was preparing for the first major release of this product since it was first released. This product was implemented to replace the existing solutions within the organization that no longer met the requirements of the business. 


\subsection{Perception of VBRE}

Three of the four interviewees were able to express how software product value was created through RE. All of the participants saw a need to align the software product with the goals of their target market,

"If any organization wants to succeed today they need really to look at their market and who they want to service and align the products with their goals."

One participant identified "working with your clients to build something that is very important" to align the goals of software development with the target market. This aligns the product to the real needs and not perceived needs of the client, "by listening to our customers, ... their challenges ... and interpret that ... a deliverable down to the end."

Another participant suggested it was hard to service a lot of industries, but that the ability to easily and simply customize the front-end allowed this goal to be achieved. However, it was also acknowledged that software product value needed to be considered from the perspective of software development management and developed within constraints,

"You have to be very careful in any software development that you are supplying the need to the market place, but you have to do that within other criteria - cost of development, length of developmentand you have to be fairly strict."

\subsection{Release Planning for Products A1 and A2}

In the past Company A developed products for the market without a specific client. This approach was unsuccessful, with the products not meeting the needs of the market and not selling. Company A moved to a development strategy that required a client to request a product or feature before it would be developed. This strategy led to a situation where new features were only made available in customer specific implementations. The problems here were two-fold; these new features could not be easily made available to other clients, and if changes needed to be made to the core product, then many customers' specific implementations needed to be released.

The role of the requirements engineer was split between both products. The Product Manager (PM) was responsible for defining business requirements and selected the set of requirements for a particular release based on the information gathered from the previous steps in the RE process. This decision was most heavily influenced by the ability to create revenue. The Development Manager (DM) was responsible for defining technical requirements and was heavily involved in the final decision making process.

Both products followed the same RE and release planning process. The formal RE process commenced with a meeting between the marketing, sales, development and support teams within the company. This group had a workshop to identify and prioritize potential features of the product. Sales represented the market in general and identified market opportunities. Additionally there was feedback from employees who had attended trade shows. Although, there was a well defined RE and release planning process for major releases, they apply an ad hoc process to handle more immediate client requirements.

The clients were the key stakeholder group for RE for both products. However, sales, implementation, operations, and development were seen as important and influential in release planning. Requirements from new and existing clients heavily influenced the direction of the product and formed the ad hoc process, "if there are specific features ... that a customer requires in order for us to win a contract ... then that gets included as part of the next [customer specific] release."

When implementing a new feature for a specific client, the PM preferred to get everyone involved in a meeting to discuss, analyze and validate the requirements. Client specific functionality was then rolled back into the core product as part of the formal release planning process. The potential functionality for Product A1 was then interpreted, verified and validated and priorities were placed on the requirements. The PM and development team held a workshop to determine what each requirement means for Product A1 in terms of development effort and impact to the system. The first question asked was if it was possible to implement the requirement. Those that could be implemented were prioritized from one and five. Revenue, product differentiation and sales were the key overarching aims in prioritizing the requirements. Where a requirement was peculiar to a client and not seen as a marketing opportunity it would remain as an add-on to the core product for the client it was originally intended and not be rolled into the core product.

\subsection{Values Applied in Requirements Selection}

Participants, for Product A1 identified three additional criteria as being important in the decision making process in release planning: $(i)$ creation of competitive advantage, (ii) preferred operating architecture, (iii) adherence to corporate software design parameters.

The results for Product A1 clearly indicate that some criteria were more important than others in the selection and prioritization of requirements for the release. The order and relative importance of the different criteria can be seen in Table 2. The market and clients of Product A1 had the most significant 
influence on the selection and prioritization of requirements for inclusion in the software. When the criteria were ranked in order of influence, four of the five criteria representing the clients and market of Product A1 appeared in the top five places. The results for how the value criteria should be optimally applied in requirements selection and prioritization for Product A1 indicate that some change would be perceived beneficial as shown in Table 3 .

Table 2 Percentage values for importance of different criteria for Product A1.

\begin{tabular}{|l|r|}
\hline Criteria & $\begin{array}{l}\text { Relative } \\
\text { importance }\end{array}$ \\
\hline 3. Stakeholder Priority of Requirement & $11.5 \%$ \\
\hline 2. Requirement's Issuer & $11.5 \%$ \\
\hline 4. Function is Promised/Sold & $9.0 \%$ \\
\hline 11. Complexity & $8.9 \%$ \\
\hline 1. Competitors & $8.8 \%$ \\
\hline 10. System Impact & $7.8 \%$ \\
\hline 12. Requirements Dependencies & $7.6 \%$ \\
\hline 7. Development Cost-Benefit & $7.3 \%$ \\
\hline 9. Delivery Date/Calendar Time & $7.3 \%$ \\
\hline 8. Resources/Competencies & $4.9 \%$ \\
\hline 14. Maintenance & $4.8 \%$ \\
\hline 13. Evolution & $4.5 \%$ \\
\hline 6. Support/Education/Training & $3.4 \%$ \\
\hline 5. Volatility & $2.7 \%$ \\
\hline
\end{tabular}

Table 3 Percentage values for optimal importance of different criteria for Product A1.

\begin{tabular}{|l|r|}
\hline Criteria & $\begin{array}{l}\text { Relative } \\
\text { importance }\end{array}$ \\
\hline 3. Stakeholder Priority of Requirement & $10.4 \%$ \\
\hline 2. Requirement's Issuer & $10.3 \%$ \\
\hline 7. Development Cost-Benefit & $9.8 \%$ \\
\hline 1. Competitors & $8.9 \%$ \\
\hline 10. System Impact & $8.8 \%$ \\
\hline 9. Delivery Date/Calendar Time & $7.8 \%$ \\
\hline 12. Requirements Dependencies & $7.3 \%$ \\
\hline 4. Function is Promised/Sold & $6.7 \%$ \\
\hline 11. Complexity & $6.4 \%$ \\
\hline 13. Evolution & $5.8 \%$ \\
\hline 14. Maintenance & $5.0 \%$ \\
\hline 5. Volatility & $4.4 \%$ \\
\hline 8. Resources/Competencies & $4.4 \%$ \\
\hline 6. Support/Education/Training & $3.8 \%$ \\
\hline
\end{tabular}

The participants for Product A1 optimally saw the criteria distributed over a tighter range. The optimal application of the criteria remained customer focused. However, this area still reported a significant change. The importance of criterion (4) if the function has been promised or sold fell five places in the ranking of criteria, while (3) the market's priority of the requirement and (2) the stakeholder responsible for issuing the requirement remained unchanged in the first two positions. The issue seen as most undervalued at the time the questionnaire was conducted was (7) the development cost-benefit of the requirement. This criterion raised five places when the criteria were ranked how the participants would like to see them applied. The most significant change in the criteria representing the developers and maintainers was a decrease in the importance of (11) the complexity of the requirement. This criterion fell five places when ranked against how the participants would like to see them applied.

The results for Product A2 can be seen in Table 4. Two additional criteria were identified as influencing the release planning process $(i)$ non custom application (Resell a solution, save costs); (ii) future financial worth/new business applications.

Table 4 Percentage values for importance of different criteria for Product A2.

\begin{tabular}{|l|r|}
\hline Criteria & $\begin{array}{l}\text { Relative } \\
\text { importance }\end{array}$ \\
\hline 4. Function is Promised/Sold & $14.5 \%$ \\
\hline 8. Resources/Competencies & $11.9 \%$ \\
\hline 1. Competitors & $11.3 \%$ \\
\hline 7. Development Cost-Benefit & $10.1 \%$ \\
\hline 3. Stakeholder Priority of Requirement & $8.5 \%$ \\
\hline 2. Requirement's Issuer & $8.3 \%$ \\
\hline 11. Complexity & $7.1 \%$ \\
\hline 9. Delivery Date/Calendar Time & $6.6 \%$ \\
\hline 10. System Impact & $6.4 \%$ \\
\hline 5. Volatility & $4.5 \%$ \\
\hline 12. Requirements Dependencies & $3.1 \%$ \\
\hline 14. Maintenance & $2.9 \%$ \\
\hline 6. Support/Education/Training & $2.6 \%$ \\
\hline 13. Evolution & $2.2 \%$ \\
\hline
\end{tabular}

The market and clients of Product A2 had the most significant influence on the selection and prioritization of requirements for inclusion in the software. When the criteria were ranked in order of influence, four criteria representing the clients and market of Product A2 appeared in the first five places. The most important criteria for Product A2 represented both the client/market and management issues. The results for how the value criteria should be optimally applied in requirements selection and prioritization for Product A2 indicated that some change would be perceived beneficial. The results can be seen in Table 5 .

Table 5 Percentage values for optimal importance of different criteria for Product A2.

\begin{tabular}{|l|r|}
\hline Criteria & $\begin{array}{l}\text { Relative } \\
\text { importance }\end{array}$ \\
\hline 1. Competitors & $13.9 \%$ \\
\hline 3. Stakeholder Priority of Requirement & $12.3 \%$ \\
\hline 8. Resources/Competencies & $10.7 \%$ \\
\hline 9. Delivery Date/Calendar Time & $10.3 \%$ \\
\hline 2. Requirement's Issuer & $7.8 \%$ \\
\hline 7. Development Cost-Benefit & $7.5 \%$ \\
\hline
\end{tabular}




\begin{tabular}{|l|r|}
\hline 4. Function is Promised/Sold & $5.8 \%$ \\
\hline 14. Maintenance & $5.6 \%$ \\
\hline 6. Support/Education/Training & $5.1 \%$ \\
\hline 11. Complexity & $5.1 \%$ \\
\hline 5. Volatility & $5.0 \%$ \\
\hline 12. Requirements Dependencies & $4.1 \%$ \\
\hline 10. System Impact & $4.0 \%$ \\
\hline 13. Evolution & $2.7 \%$ \\
\hline
\end{tabular}

The optimal application of the criteria remained customer focused. However, this area reported a significant change in the focus of these criteria. The importance of criterion (4), if the function has been promised or sold, fell six places in the ranking of criteria going from the most important to the least important customer/market criterion.

The management issue perceived as most undervalued at the time the questionnaire was conducted was (9) the impact the requirement has on delivery date. This criterion rose four places when the criteria were ranked how the participants would like to see them applied. The participants for Product A2 optimally saw the development criteria distributed over a tighter range. The difference between the most and least important development criteria today is $4.7 \%$ points, while optimally was perceived as $1.4 \%$ points.

\subsection{Stakeholder Influence in RE}

The results for Products A1 and A2, when grouped by stakeholder group, clearly indicated that some stakeholder groups were more important than others in the selection and prioritization of requirements for a release. The results for how the value criteria should be optimally applied in requirements selection and prioritization for all products indicated that some change would be perceived beneficial.

Table 6 Application of criteria from major perspectives for Product A1.

\begin{tabular}{|l|c|c|c|c|}
\cline { 2 - 5 } \multicolumn{1}{c|}{} & \multicolumn{2}{c|}{ 14 Criteria (\%) } & \multicolumn{2}{c|}{$\begin{array}{c}\text { Including } \\
\text { Additional (\%) }\end{array}$} \\
\cline { 2 - 5 } & Today & $\begin{array}{c}\text { Optima } \\
\text { I }\end{array}$ & Today & $\begin{array}{c}\text { Optima } \\
\text { I }\end{array}$ \\
\hline $\begin{array}{l}\text { External } \\
\text { Market/ Cust }\end{array}$ & 43 & 41 & 45 & 42 \\
\hline $\begin{array}{l}\text { Company } \\
\text { Management }\end{array}$ & 23 & 26 & 23 & 27 \\
\hline $\begin{array}{l}\text { Development/ } \\
\text { Maintenance }\end{array}$ & 34 & 33 & 32 & 31 \\
\hline
\end{tabular}

For Product A1, three criteria were added that influence release planning. These were applied to stakeholder groups decided by the researchers. Both the preferred operating architecture and adherence to corporate software design parameters were assigned to the management perspective. The creation of competitive advantage was applied to the external market/customer perspective. The results, both including and not including the additional criterion, can be seen in Table 6. Product A1 had a strong customer/market focus with this group having the strongest influence on release planning for the product. The development perspective was second most important influencer when selecting and prioritizing requirements, while management issues were least important. While the participants in the study felt that optimally the ranking of these groups would remain the same, it was felt that the opinions of the groups should be valued more equally.

As two additional criteria that influence release planning were identified for Product A2, they were applied to stakeholder groups decided by the researcher. Both making a resalable [sic] solution and future financial worth/new business applications were assigned to the management perspective. The results, both including and not including the additional criteria, can be seen in Table 7 .

Table 7 Application of criteria from major perspectives for Product A2.

\begin{tabular}{|l|c|c|c|c|}
\cline { 2 - 5 } \multicolumn{1}{c|}{} & \multicolumn{2}{c|}{14 Criteria (\%) } & \multicolumn{2}{c|}{$\begin{array}{c}\text { Including } \\
\text { Additional (\%) }\end{array}$} \\
\cline { 2 - 5 } \multicolumn{1}{c|}{} & Today & Optimal & Today & Optimal \\
\hline $\begin{array}{l}\text { External } \\
\text { Market/ Cust }\end{array}$ & 47 & 42 & 46 & 40 \\
\hline $\begin{array}{l}\text { Company } \\
\text { Management }\end{array}$ & 31 & 36 & 33 & 37 \\
\hline $\begin{array}{l}\text { Development/ } \\
\text { Maintenance }\end{array}$ & 22 & 23 & 21 & 22 \\
\hline
\end{tabular}

Product A2 has a strong customer/market focus with this group having the strongest influence in release planning for the product. The management perspective was the second most important influencer when selecting and prioritizing requirements, while development and maintenance issues were least important. The participants in the study saw the release planning being conducted more effectively with a small decrease in the influence of the external market/customer and an increase in the influence of the company management.

\section{Discussion of Results}

Our results show that there was no silver bullet for creating software product value through RE identified by the interview participants. While between them they raised the perspectives of each of the key stakeholder groups, it appeared that the value propositions that influenced their decision making process were more intrinsic than part of an explicitly planned process.

\subsection{Release Planning in Industry}

Release planning for both Products A1 and A2 was 
very focused towards meeting client objectives. Client specific versions of the software acted as a testing ground for requirements and are considered to represent real needs of the market. Selective and controlled rolling of these requirements into the software product core allowed the most suitable requirements to be released to a market that is better understood. The processes followed for both products A1 and A2 involved bringing the success critical stakeholders together so that a common understanding of requirements could be found. The understanding gained then acted as a base for further analysis. The PM was then responsible for taking all of these perspectives and information on board in making the final decision as to what should be implemented.

\subsection{Values Applied in Requirements Selection}

The maturity of the product had a big influence on the importance of the criteria applied in release planning. Product A1 had been evolving over the past 10 years, whereas Product A2 was much newer at two years.

In the external market/client space Product A1 was established, however, Product A2 was still trying to gain credibility within the market place. This can be seen through the most important criteria representing this stakeholder group, for Product A1 these were (3) the stakeholders' prioritization of the requirement and (2) the party responsible for issuing the requirement, while for Product A2 these were (4) whether the function has been promised or sold and (1) the status of competitors with respect to the requirement.

Similarly, (8) the resources and competencies of development personnel were more important for Product A2 than Product A1. As Product A1 was more mature, expertise existed within the company to support this product. However, Product A2 took the company through "unknown waters".

Development cost-benefit (7) was also a bigger issue for Product A2 as a lot of money has been spent in its early development and management was more cautious about seeing revenue, whereas Product A1 had become highly profitable for Company A. Looking at the optimal application of criteria, the PM felt that the development cost-benefit (7) for Product A1 was perceived as undervalued due to the time and resources being put into other projects. There was a perception within the organization that the highly profitable Product A1 would loose competitive advantage while resources were focused elsewhere. However, the PM also conceded that there was a greater desire to build functionality with less concern over the revenue it would generate.

The increase in the importance of (9) the impact a criterion has on the delivery date for both Product A1 and Product A2 can be explained with reference to how it helps to create a positive market perception when the company is first to bring new functionality to the market place. The massive decrease in the importance of (4) the functionality being promised or sold can be explained with reference to the fact that Company A would like to start taking a more structured approach to bringing new functionality into the market place. Rather than developing client specific versions of the software, the company would like to see more controlled release planning, which implements functionality and releases it to the general market.

\subsection{Stakeholder Influence in RE}

The results for the RQ4 only further highlighted the results of the other research questions - the clients were the most critical group in creating software product value. With regard to the influence of the stakeholder groups on the requirements, the PM felt that the influence of the client/market perspective was appropriate. As more standard development tools and techniques were used for Product A2, the PM felt that development and maintenance issues were not as critical as they were for Product A1.

\section{Validity Threats}

The results of this study must be interpreted with caution as two products that we investigated are not a representative sample of the software development industry. The small number of people involved in the decision making process for the inclusion of a requirement in a software system has limited the number of possible responses for each product.

We asked participants to use evaluate the need for further criteria, however it is easier for the participants to agree with the set of criteria identified by the researchers than disagree. This is partially taken care of by allowing the participants to assign a relative importance of zero or propose new criteria where they see fit. Another potential threat is related to the questionnaire. It is always difficult to know whether the respondents have understood the questions as intended and in a similar fashion to one another. This threat was partially addressed in the third stage of this study where the results were presented to the product manager for confirmation and discussion with the researcher.

\section{Conclusions and Future Study}

VBRE is a new area of study and is still in the theory building stage. This study has shown that some criteria are more important than others in the selection of requirements to include in a specific project or release. Moreover, this study has shown that the client 
and market perspectives are more influential than the business and technical perspectives. Based on our investigation, the following points are illustrated:

RQ1: There is no silver bullet for creating software product value through requirements selection. Intrinsic knowledge guides decision-makers in this process, but the process followed is not well understood.

RQ2: The requirements of the market are best understood and represented by clients within the market. Aligning development to these needs ensures that market requirements are met; however, the development company needs to ensure that its needs are also met.

RQ3: While the focus changes slightly, criteria representing the market and specific clients' requirements are the most influential in release planning decision making.

RQ4: The client market perspective is the most influential in the selection of requirements for a release. Where standard development tools and techniques are used the development and maintenance perspective is less influential than management, but they are otherwise similar.

These conclusions have some implications. First, as the creation of software product value through requirements selection is not very well understood it cannot be managed in the most effective way. Greater insight into how value is created through release planning would allow this process to be more effectively managed. Secondly the management of software product value is dependant on the context in which the product exists. Factors such as: the maturity of the product, the marketplace in which it exists and the development tools and methods available influence the criteria that decide whether a requirement is included in a specific project or release. A young product will have a greater need to recoup initial development costs, a more competitive marketplace requires more adaptive development, and standard software tools and techniques speed up development and reduce development resource issues. However, further research is required to determine what aspects of a software product's context influence the decisionmaking criteria. These issues pose great challenges when it comes to creating software product value through requirements selection.

\section{References}

[1] D Alwis, V Hlupic, R Fitzgerald, "Intellectual Capital Factors that Impact of Value Creation", 25th Int. Conf on Information Technology Interfaces, Croatia, pp. 411-416, 2003

[2] JC Anderson and JA Narus, "Business Marketing: Understanding What Customers Value", Harvard Business Review, November-December 1998
[3] B Boehm, "Value-based Software Engineering: Overview and Agenda", in Value Based Software Engineering, S Biffl, A Aurum, B Boehm, H Erdogmus, P Grünbacher, (Eds), pp. 3-14, Springer, Germany, 2005a

[4] B Boehm, "Value-based SE: Seven Key Elements and Ethical Considerations', in Value Based Software Engineering, S Biffl, A Aurum, B Boehm, H Erdogmus, P Grünbacher, (Eds), pp. 109-134, Springer, Germany 2005b

[5] TR Browning, JJ Deyst, SD Eppinger, and DW Whitney, "Adding Value in Product Development by Creating Information and Reducing Risk", IEEE Transactions on Engineering Management, 49(4): 428-442, 2002

[6] P Carlshamre, "Release Planning in Market-driven Software Product Development: Provoking an Understanding", Requirements Engineering, 7:139-151, 2002

[7] P Carlshamre, K Sandahl, M Lindvall, B Regnell, and J Natt och Dag, "An Industrial Survey of Requirements Interdependencies in Software Product Release Planning", Int Symp on Empirical Software Eng, CA, pp. 84-92, 2001

[8] \& Dahlstedt., A Persson, "Requirements Interdependencies - Moulding the State of Research into a Research Agenda", 9th Int Workshop on Requirements Engineering - Foundation of Software Quality Klagenfurt/Velden, Austria, pp. 71-80, 2003

[9] J Gordjin and JM Akkerman, "Value-based Requirements Engineering: Exploring Innovative e-commerce Ideas", Requirements Engineering, 8(2):114-134, July 2005

[10] J Karlsson, C Wohlin and B Regnell, "An Evaluation of Methods for Prioritizing Software Requirements", Information and Software Tech, 39(14-15):939-947, 1998

[11] S Maurice, G Ruhe, O Saliu, A Ngo-The and R Brassard, "Decision support for Value-based Software Release Planning', in Value Based Software Engineering, S Biffl, A Aurum, B Boehm, H Erdogmus, P Grünbacher, (Eds.), pp. 253-268, Springer, Germany, 2005

[12] JF Nunamaker, RO Briggs, and GJ De Vreede, "Enhancing organizations' Intellectual Bandwidth: The Quest for Fast and Effective Value Creation", Special issue: Journal of management information systems, 17(3):3-8, 2001

[13] G Ruhe, and D Greer, " Quantitative Studies in Software Release Planning under Risk and Resource Constraints", Int Symp on Empirical Software Eng, CA, pp. 262-271, 2003

[14] The Standish Group, 1995, The CHAOS Report, Available: http://www.standishgroup.com/

[15] The Standish Group, 2004, The CHAOS Report, Available: http://www.standishgroup.com/

[16] J Thorp, The Information Paradox, McGraw Hill, 1998

[17] C Wohlin, and A Aurum, "Criteria for Selecting Software Requirements to Create Product Value: An Industrial Empirical Study", in Value Based Software Engineering, S Biffl, A Aurum, B Boehm, H Erdogmus, P Grünbacher, (Eds.), pp. 183-206 Springer, Germany, 2005a

[18] C Wohlin, and A Aurum, "What is Important When Deciding to Include a Software Requirement in a Project or Release?" Int Symp on Empirical Software Eng, Noosa Heads, Australia, November 2005b 